\title{
Pulmonary platelet aggregates: Possible cause of sudden peroperative death in adults undergoing liver transplantation
}

\author{
E A Sankey, J Crow, SV Mallett, RJ Alcock, L More, AK Burroughs, K Rolles
}

\begin{abstract}
Aims: To determine if massive pulmonary platelet thromboembolism is a common cause of peroperative death following liver transplantation; and to compare the incidence of this event with patients dying after non-transplantation procedures.
\end{abstract}

Methods: Necropsy tissues from all patients dying within 10 days of operation during the past three and a half years were studied (six liver transplantations and 13 unrelated operations). Haematoxylin and eosin stained sections of all tissues were examined. Additional sections of lung tissue were immunostained for constituents of thrombus (fibrin and platelets).

Results: At necropsy the lungs from all six liver transplant recipients were heavy with a rubbery texture and little oedema fluid. Those from non-transplantation patients appeared normal or very oedematous. Microscopic examination showed that there were numerous platelet aggregates occluding pulmonary capillaries in all six transplant recipients, but in only three of the non-transplant patients. These thrombi were numerous in patients dying during surgery and the number was underestimated in routine sections because of the surrounding capillary congestion. Detection was improved by immunostaining for platelets with factor XIIIA and platelet glycoprotein IIIa.

Conclusions: Massive platelet thromboembolism is a likely cause of death in patients dying unexpectedly following recent liver transplantation. Non-transplantation patients dying during surgery who show similar appearances usually have conditions known to have a high risk of thrombosis or embolism (cement hypotension syndrome and disseminated intravascular coagulation). The cause of this extensive platelet activation in liver transplant recipients is uncertain and may be multifactorial. The unusual rubbery consistency of the lungs on macroscopic examination could alert the pathologist to the underlying condition. Immunostaining for platelets improves the detection microscopically.

(F Clin Pathol 1993;46:222-227)
Liver transplantation is performed with considerable success in many centres throughout the world. In over 100 adult orthotopic liver transplantations carried out at the Royal Free Hospital there have been minimal surgical complications but three patients died unexpectedly during the operation. At necropsy numerous platelet aggregates were found occluding pulmonary capillaries. Similar platelet thrombi were recently described in the lungs of children dying during liver transplantation. ${ }^{1}$

Although pulmonary microembolism is a recognised complication of several conditions including disseminated intravascular coagulation (DIC), multiple trauma and major orthopaedic and vascular surgery, ${ }^{23}$ an association with transplantation has not been widely established. It is also unknown if platelet thrombi are found more commonly in liver transplant recipients who make a poor recovery and die soon after operation.

We have reviewed all perioperative deaths in adults up to the tenth postoperative day to determine if such platelet thrombi are a common finding in transplant related deaths or if they are a more generalised finding in patients dying suddenly during, or after, other operations.

\section{Methods}

Of the 100 liver transplantation operations undertaken at the Royal Free Hospital there have been 27 transplantation related deaths, 10 of which have occurred within 10 days of surgery. Of these, two had a necropsy refused on religious grounds, two showed extensive post mortem autolysis and were unsuitable for this study, and the remaining six were examined in detail.

During the same period 13 patients died within 10 days of a non-transplantation operation and underwent necropsy. Details of the post mortem findings and histology were compared with the transplant cases. The clinical details of each group of patients are summarised in tables 1 and 2 .

The average age of the transplantation group was 50 years (range $37-57$ years) with equal numbers of men and women. Death occurred from day 0 to day 8 postoperatively. No patients had known operative risks apart from case 2 who had mild exertional dyspnoea and a moderate obstructive lung function picture (FEV1:1.411 60\% predicted, 
Table 1 Clinical details of liver transplant recipients

\begin{tabular}{|c|c|c|c|c|}
\hline Age/Sex & Original disease & $\begin{array}{l}\text { Base line } \\
\text { liver biopsy } \\
\text { specimen }\end{array}$ & $\begin{array}{l}\text { Day of } \\
\text { death }\end{array}$ & Operative details \\
\hline 1) $37 \mathrm{~m}$ & $\begin{array}{l}\text { Cryptogenic } \\
\text { cirrhosis }\end{array}$ & Fat +++ & 0 & $\begin{array}{l}\uparrow \text { Pulmonary arterial } \\
\text { pressure (PAP), cardiac } \\
\text { arrest } 90 \text { seconds after } \\
\text { revascularisation } \uparrow \mathrm{K}+ \\
8-9 \mathrm{mmol} / 1\end{array}$ \\
\hline 2) $57 \mathrm{f}$ & $\begin{array}{l}\text { Primary biliary } \\
\text { cirrhosis }\end{array}$ & Normal & 0 & $\begin{array}{l}\uparrow \mathrm{PAP}, \text { cardiac arrest } \\
\text { prior to reanastomosis } \\
\text { Underlying pulmonary } \\
\text { hypertension }\end{array}$ \\
\hline 3) $52 \mathrm{~m}$ & $\begin{array}{l}\text { Cryptogenic } \\
\text { cirrhosis }\end{array}$ & Normal & 0 & $\begin{array}{l}\uparrow \mathrm{PAP} \text {, cardiac arrest, } \\
\text { resuscitated for } 3 \text { hours }\end{array}$ \\
\hline 4) $42 \mathrm{f}$ & $\begin{array}{l}\text { Primary biliary } \\
\text { cirrhosis }\end{array}$ & Normal & 2 & $\begin{array}{l}\text { Hypotension requiring } \\
\text { postoperative inotropic } \\
\text { support and coagulopathy }\end{array}$ \\
\hline 5) $55 \mathrm{~m}$ & $\begin{array}{l}\text { Alcoholic and } \\
\text { Hepatitis B virus } \\
\text { cirrhosis }\end{array}$ & Normal & 4 & $\begin{array}{l}\text { Re-operation at } 6 \text { hours } \\
\text { for haemorrhage, } \\
\text { inotropic support } \\
\text { required after 2nd } \\
\text { operation }\end{array}$ \\
\hline 6) $55 \mathrm{f}$ & $\begin{array}{l}\text { Primary biliary } \\
\text { cirrhosis }\end{array}$ & Normal & 8 & $\begin{array}{l}\text { Inotropic support } \\
\text { required during and } \\
\text { postoperatively } \\
\text { Fall in platelets, cardiac arrest }\end{array}$ \\
\hline
\end{tabular}

FVC:2.61 93\% predicted). After anaesthetic induction this patient was found to have severe pulmonary hypertension. Of the patients dying postoperatively, cases 4 and 6 required intraoperative and postoperative inotropic support and both developed a recognised coagulopathy before death. Case 5 required further surgery at six hours to arrest bleeding. Inotropic support was needed after the second operation, but no clinical evidence for coagulopathy was present at the time of death.

The average age of the non-transplant group was 69 years (range 24-89 years), seven men and six women. Death occurred from day 0 to day 6 postoperatively. The 24 year old woman with amniotic fluid embolism (case 7) was about to die before surgery and underwent an emergency hysterectomy in an attempt to save her child. All other patients were considered fit for anaesthetic.

PEROPERATIVE OBSERVATIONS

In an attempt to reduce intraoperative blood loss patients with abnormal clotting variables or demonstrable fibrinolysis on thromboelastography were given an intravenous antifibrinolytic drug (Trasylol) during surgery. ${ }^{4}$ In our study three of the six patients received this drug, two of whom died during surgery. Preoperative platelet counts in all patients were considered adequate to allow normal haemostasis (table 3). Subsequent platelet counts determined the need for platelet transfusions, and these were given to cases 3 (only during resuscitation), 4 , and 5 . During the anhepatic stage of the operation there was an expected fall in cardiac output with a compensatory rise in peripheral resistance. Venovenous bypass was not used. In those patients who died during surgery there was a sudden and unrecoverable loss of cardiac output. In the patient with pre-existing pulmonary hypertension (case 2) this occurred before the donor liver was revascularised. In patients surviving for a few days after operation no catastrophic intraoperative event was observed but they required increasing post-

Table 2 Clinical details of non-transplant recipients

\begin{tabular}{|c|c|c|c|}
\hline Age/Sex & Operation & Day of death & Cause of death \\
\hline 7) $24 \mathrm{f}$ & Pregnant hysterectomy & 0 & $\begin{array}{l}\text { Amniotic fluid embolism, } \\
\text { disseminated intravascular } \\
\text { coagulation }\end{array}$ \\
\hline 8) $89 \mathrm{~m}$ & Hip replacement & 0 & $\begin{array}{l}\text { "Cement hypotension" during } \\
\text { operation }\end{array}$ \\
\hline 9) $81 \mathrm{f}$ & Hip replacement & 0 & $\begin{array}{l}\text { "Cement hypotension" during } \\
\text { operation }\end{array}$ \\
\hline 10) $73 \mathrm{f}$ & Femoral artery bypass & 0 & $\begin{array}{l}\text { ECG changes during } \\
\text { operation, postoperative } \\
\text { cardiac arrest }\end{array}$ \\
\hline 11) $32 \mathrm{~m}$ & $\begin{array}{l}\text { Removal of arteriovenous } \\
\text { malformation }\end{array}$ & 1 & Cerebral oedema \\
\hline 12) $58 \mathrm{~m}$ & $\begin{array}{l}\text { Gastrectomy for infarcted } \\
\text { stomach post embolisation }\end{array}$ & 1 & Acute pancreatitis \\
\hline 13) $59 \mathrm{~m}$ & $\begin{array}{l}\text { Cholecystectomy } \\
\text { (perforated) }\end{array}$ & 2 & Septicaemia \\
\hline 14) $89 \mathrm{f}$ & $\begin{array}{l}\text { Colectomy for } \\
\text { diverticular disease }\end{array}$ & 2 & Myocardial infarction \\
\hline 15) $61 \mathrm{~m}$ & $\begin{array}{l}\text { Transurethral resection of } \\
\text { prostate }\end{array}$ & 2 & $\begin{array}{l}\text { Large thromboemboli } \\
\text { both pulmonary arteries }\end{array}$ \\
\hline 16) $89 \mathrm{~m}$ & $\begin{array}{l}\text { Colectomy for sigmoid } \\
\text { volvulus }\end{array}$ & 2 & Myocardial infarction \\
\hline 17) $88 \mathrm{f}$ & Hip replacement & 3 & $\begin{array}{l}\text { "Cement hypotension" during } \\
\text { operation, never regained } \\
\text { consciousness }\end{array}$ \\
\hline 18) $70 \mathrm{f}$ & $\begin{array}{l}\text { Clipping of cerebral } \\
\text { aneurysm }\end{array}$ & 3 & Subarachnoid haemorrhage \\
\hline 19) $80 \mathrm{~m}$ & $\begin{array}{l}\text { Hemicolectomy for } \\
\text { haemorrhage }\end{array}$ & 6 & Cardiac failure \\
\hline
\end{tabular}


Table 3 Random platelet counts in liver transplant recipients

\begin{tabular}{lllll}
\hline Case No & $\begin{array}{l}\text { Lowest preoperative } \\
\text { platelet count } \\
\left(\times 10^{9} / l\right)\end{array}$ & $\begin{array}{l}\text { Lowest intraoperative } \\
\text { platelet } \\
\text { count }\left(\times 10^{9} / l\right)\end{array}$ & $\begin{array}{l}\text { Last platelet } \\
\text { count before } \\
\text { death }\left(\times 10^{-9} / l\right)\end{array}$ & $\begin{array}{l}\text { Survival from } \\
\text { start of } \\
\text { operation } \\
\text { (days) }\end{array}$ \\
\hline 1 & 122 & 112 & - & 0 \\
2 & 130 & - & - & 0 \\
3 & 178 & 50 & 106 & 0 \\
4 & 122 & 99 & 19 & 3 \\
5 & 158 & 61 & 22 & 6 \\
6 & 205 & 121 & & \\
\hline
\end{tabular}

operative inotropic support until death. Four non-transplantation patients died during, or on the day of, operation. Case 7, as described above, was already dying before surgery. In two of the three cases of cement hypotension syndrome (cases 8 and 9) there was an unrecoverable fall in blood pressure at the time of insertion of the cement. The third patient (case 17) improved, but never regained consciousness and died three days later. Case 10 showed electrocardiographic abnormalities during operation and died of cardiac arrest a few hours postoperatively. No perioperative complications were noted in the remaining eight non-transplantation patients.

Full necropsies were conducted in all cases. Tissue samples were fixed in $10 \%$ buffered formalin and processed routinely. Lung tissue fixed in glutaraldehyde from two transplantation cases was also available for electron microscopic examination. Sections of all tissues were stained with haematoxylin and eosin. Sections of lung were also immunostained to demonstrate platelet and thrombus constituents. Platelet thrombi were demonstrated with monoclonal platelet glycoprotein IIIa (PGIIIa) (dilution 1 in 5, Dako Ltd, High Wycombe, Bucks, England and monoclonal factor XIIIA (dilution 1 in 400, Behring Diagnostics, Hounslow) which also immunostained cross-linked fibrin. Polyclonal antibodies to fibrinogen (dilution 1 in 1000, Dako Ltd) were used to demonstrate fibrinogen. In an attempt to identify epithelial fragments of possible liver or biliary origin, lungs from liver transplant recipients were also stained with periodic acid Schiff to demonstrate glycogen, Gordon and Sweet's silver reticulin stain, and immunostained for epithelial markers (monoclonal CAM 5.2, prediluted, Becton Dickinson, Oxford, and monoclonal MNF116, dilution 1 in 100 , Dako Ltd).

Where available, baseline donor liver biopsy specimens, taken half an hour after revascularisation, were examined.

\section{Results}

Case 7, who had DIC, showed fibrin and platelet thrombi in organs other than lung (liver, bowel, thyroid and pituitary). No thrombi were identified in any other tissue examined from the transplant or remaining non-transplant patients.

MACROSCOPIC APPEARANCES OF THE LUNGS There were notable differences between the lungs from patients who had undergone liver transplantation compared with other operations. In liver transplant recipients the lungs were heavy, with an average weight of $878 \mathrm{~g}$ and a range of 700-1250 g. The consistency was unusually rubbery and appeared congested, much like the appearance of lungs seen in adult respiratory distress syndrome. Despite the weight of the lungs, pulmonary oedema could not be easily expressed from the tissues. Macroscopic pulmonary emboli were not identified in any of the patients.

In six patients who had died after other operations, the appearances of the lungs were normal with weights of $250-450 \mathrm{~g}$. Seven patients had noticeable pulmonary oedema with fluid easily expressed from the tissues and weights of $500-900 \mathrm{~g}$. In two cases thromboemboli were identified macroscopically in large vessels.

\section{MICROSCOPIC APPEARANCES}

Sections of lung from liver transplant recipients, particularly those who had died suddenly during the operation, showed congested and dilated capillaries with extensive intravascular thrombi occluding small arterioles and alveolar capillaries of all lobes. These thrombi appeared eosinophilic or slightly basophilic with a granular or fine fibrillary texture on haematoxylin and eosin staining (fig 1). These capillary thrombi showed positive immunostaining for platelet markers, factor XIIIA, and PGIIIa (fig 2). Some thrombi contained irregular, granular basophilic material reminiscent of cell debris, admixed with leucocytes. Staining for glycogen, reticulin and immunostaining with CAM $5 \cdot 2$ and MNF116 failed to identify admixed fragments resembling hepatic or biliary tissue in the thrombi. Occasional large and medium sized arteries were partially occluded by similar thrombus. Immunostaining for fibrinogen was seen in many large and medium sized arteries and some capillaries containing thrombus. This was in contrast to the localisation of factor XIIIA and PGIIIa immunostaining which was present almost exclusively in alveolar capillaries and small arterioles. The wide extent of the intravascular thrombosis was emphasised by this staining technique. Tissue prepared for electron microscopy was suboptimally preserved due to post mortem autolysis, but no features resembling hepatocyte cytoplasm were identified admixed with thrombus. No other organs showed similar fibrin or platelet thrombi.

The donor livers were examined in each case and appeared normal apart from that in case 1 . This showed severe fatty change and some haemorrhage which was more than is normally encountered in baseline biopsy specimens.

In addition to the above changes, case 2 showed mild and patchy features of fibrosing alveolitis and rather pronounced focal cryptogenic organising pneumonitis (COP). The pulmonary arteries showed intimal thickening and medial hypertrophy in keeping with pulmonary hypertension. 
Figure 1 Numerous platelet thrombi occluding small pulmonary capillaries (arrow). $A$ larger artery (upper left) shows no thrombus haematoxylin and eosin. Insert: Granular and fibrillar thrombus distending the lumen of a small capillary.

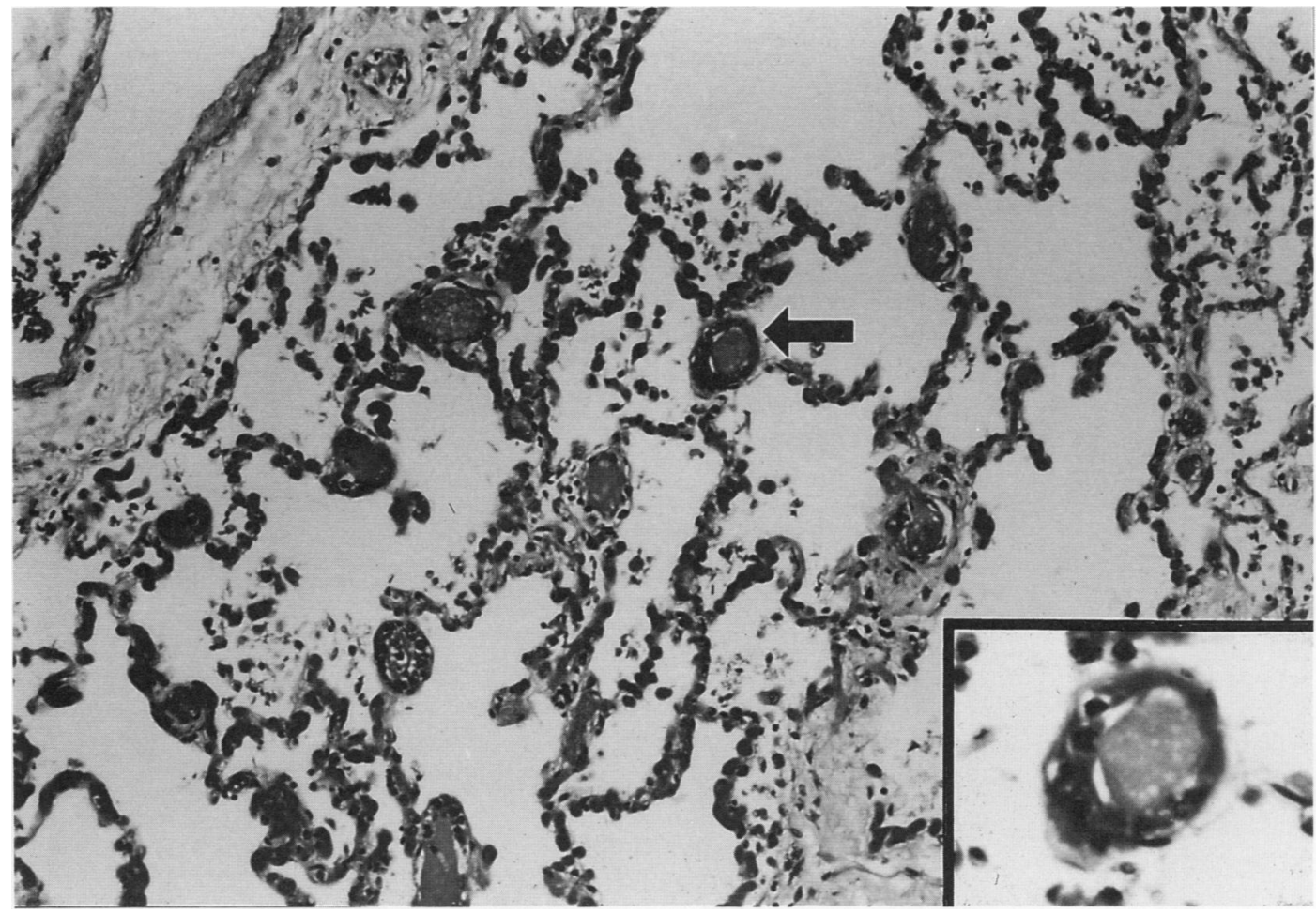

In contrast to the liver transplant recipients, lungs from non-transplant patients showed less congestion and more pulmonary oedema. Only two of the four patients who died suddenly on the day of the operation showed widespread capillary thrombi (cases 7 and 8). One patient had DIC, the other had cement hypotension syndrome. A second patient dying of cement hypotension syndrome showed only moderate numbers of capillary plugs (case 9). These thrombi immunostained positively for factor XIIIA and PGIIIa. The three patients who had died of cement hypotension syndrome (cases 8,9 , and 17) all showed extensive fat emboli within small pulmonary capillaries. Patients dying later rarely showed positive immunostaining in capillaries.
Random platelet counts taken on all liver transplant recipients are presented in table 3 . A fall in the intraoperative platelet count was seen in all cases. In most cases this appeared small, however, the counts represented a random sample taken at the start of the operation and did not reflect the true peripheral blood count after haemodynamic collapse of the patient. In case 3 resuscitation was prolonged and visible consumption of platelets was seen as the counts fell from 178 to $50 \times 10^{9} / 1$ over three hours. During this time 10 Units of platelets were transfused. Most patients who survived several days after surgery received platelet infusions (cases 4 and 5) and eventually developed a recognisable coagulopathy terminally with evidence of fibrinogen degradation products (cases 4 and 6).

Figure 2 Platelet thrombi immunostained with factor XIILA showing extensive thrombosis of pulmonary capillaries $(x 400)$.

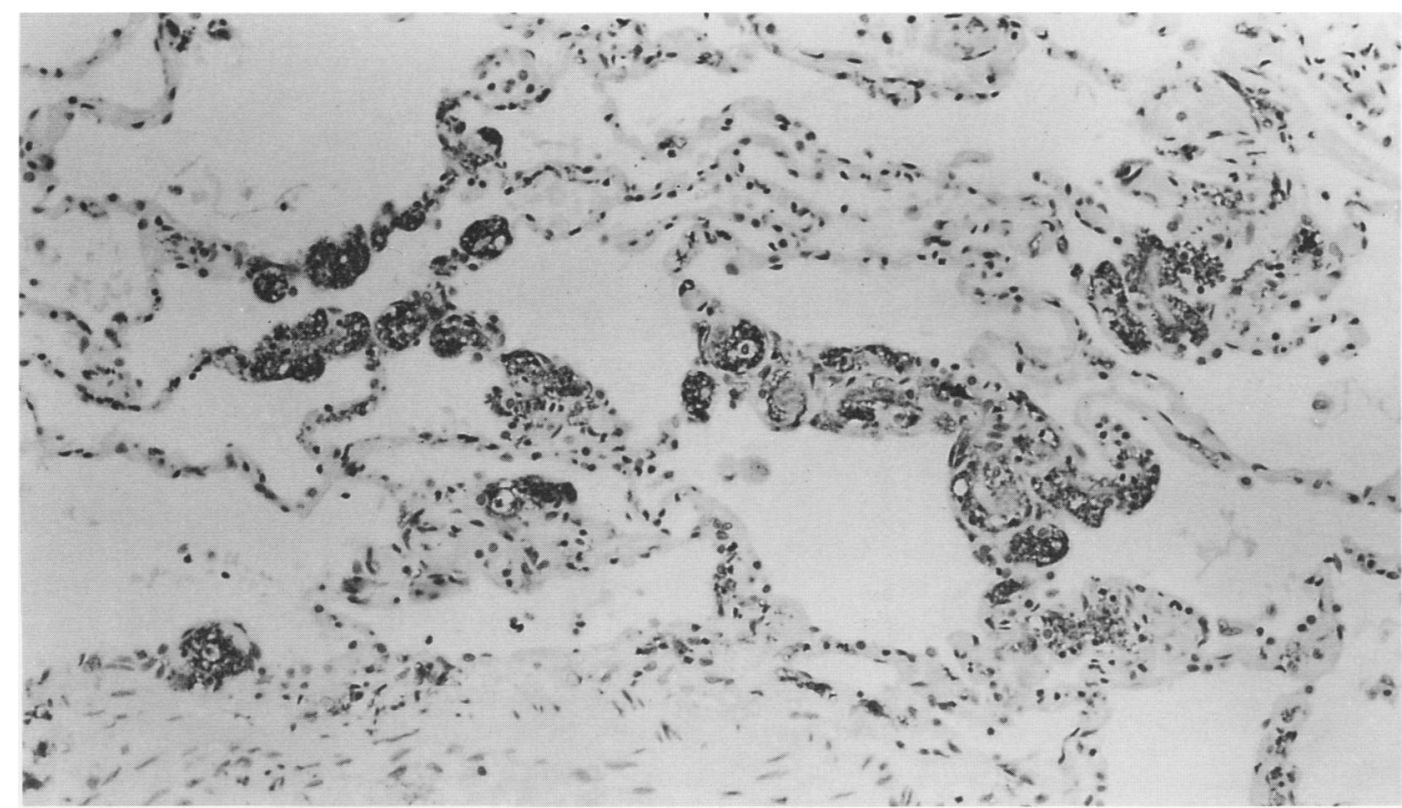




\section{Discussion}

This study has shown that there is a high incidence of platelet microemboli in the lungs of patients who die suddenly during operation. Non-transplant patients who showed these changes had a known coagulopathy or recognised risk of embolic disease. ${ }^{3}$ Patients undergoing liver transplantation had no known similar risk factors, yet developed widespread and fatal pulmonary thrombosis. The platelet thrombi predominantly occluded small pulmonary capillaries and were admixed with variable amounts of fibrin. Similar thrombi were less common in postoperative deaths, although they occurred in liver transplant recipients up to eight days after transplantation. They were not found in other organs of the body in transplant recipients and thus did not seem to represent part of a more widespread disseminated intravascular coagulation (DIC). In patients dying acutely, the sudden and profound fall in cardiac output, associated, in most cases with a considerably raised pulmonary arterial pressure, suggested that intrapulmonary obstruction by thrombi explained the failure of resuscitation attempts.

Interpretation of the fall in platelet counts is difficult and complicated by several factors. The samples were random and do not reflect counts immediately after surgery or after haemodynamic collapse of the patient, except in case 3 . In this case repeated blood counts during resuscitation documented a clear consumption of platelets before death. In the patients surviving several days, postoperative factors, such as further surgery for haemorrhage, differing numbers of platelet infusions, and the development of a recognisable coagulopathy terminally, make interpretation inaccurate and detract from the fact that the patients were haemodynamically unstable immediately after surgery.

The cause of massive, widespread activation of platelet aggregation in liver transplant recipients is unclear. One possibility is that release of tissue thromboplastin or cell debris from the ischaemic donor liver may activate platelet aggregation and lead to microembolism. Tissue thromboplastin and activated thrombin have been shown to produce pulmonary microembolism in experimental animals. ${ }^{5-8}$ The baseline biopsy specimen appearances of only one donor liver (case 1) showed extensive fatty change compatible with ischaemia; the others were unremarkable. In an attempt to reduce this effect the donor liver is flushed with albumin solution before reperfusion. Patients who arrest at the time of reperfusion due to a combination of cold, acidotic, and hyperkalaemic fluid entering the circulation are usually successfully resuscitated. In case 2 cardiovascular collapse occurred before revascularisation of the donor liver. No thromboplastin or cell debris would have entered the circulation of this patient. Specific staining for hepatocytes or biliary epithelium failed to identify cell debris within pulmonary capillaries of any of the patients. Gosseye et al. also failed to demonstrate cell debris within capillaries in children dying during liver transplantation. ${ }^{1}$

Many animal studies have demonstrated the ability of injected endotoxin ${ }^{9-11}$ to cause platelet thrombi within the lungs. A study performed by Miyata $e t a l^{12}$ showed an accumulation of endotoxin during the anhepatic stage in patients undergoing liver transplantation. This did not correlate with the duration of the anhepatic stage but did correlate with the need for perioperative platelet transfusions, ventilator dependency postoperatively, and one month case fatality. From these clinical data it seems likely that endotoxin caused platelet consumption and aggregation in the lungs of these patients, but the histological appearance of the lungs was not documented. This mechanism of platelet aggregation would not require the reconnection of the donor liver to produce an effect and may offer an explanation for our observations.

Cross-clamping of the aorta during emergency surgery has been shown to lead to a raised incidence of pulmonary microembolism. ${ }^{2}$ Similar experimental procedures on animals cause a significant fall in serum fibrinogen and result in some fibrin and numerous platelet thrombi and aggregates within the lungs. ${ }^{13} 14$ The mechanism is poorly understood but thrombosis in these cases was thought to occur within the inferior vena cava as a result of trauma to the endothelium and stasis. ${ }^{14}$ During liver transplantation the inferior vena cava is cross-clamped and some degree of endothelial trauma and circulatory stasis are unavoidable. This mechanism may have contributed to thrombus formation in our patients, although it cannot explain the formation of platelet aggregates in case 2 who collapsed before release of the inferior vena cava clamp. This patient also had additional pulmonary pathology, and an alternative, possibly local, mechanism of activation may have occurred.

Hypoxia, ${ }^{15}$ metabolic acidosis, ${ }^{16}$ and chronic lung disease ${ }^{17}$ may result in a local activation of platelet aggregation in the lungs. This is unlikely to have contributed in our cases except in case 2, as particular care was taken to maintain a stable acid base status and oxygen delivery during transplantation.

Platelet thrombi may form extremely rapidly. Stimulation of $\alpha$-adrenergic receptors in mice resulted in the accumulation of platelet aggregates in the lungs within $10 \mathrm{sec}-$ onds. ${ }^{18}$ Other mechanisms may take several minutes or hours. It was two hours before fibrin thrombi were detected following immune complex mediated DIC, ${ }^{19}$ and it is unlikely that this mechanism would explain the formation of microthrombi seen in our patients.

Patients with liver disease are prone to develop microthrombi. ${ }^{20} \mathrm{~A}$ necropsy study by Oka et $a l^{20}$ showed that $50-60 \%$ of patients with various different liver diseases had microthrombi and classic thrombi in one or more organs. Patients with portal hypertension are also at increased risk of developing pulmonary hypertension, ${ }^{21}$ one of the postulated mechanisms being recurrent microemboli. During liver transplantation the 
coagulation status of patients is monitored using serial thromboelastography. No evidence of hypercoagulability was identified in our patients at any stage. Antifibrinolytic drugs were used during surgery to reduce blood loss in patients with abnormal clotting variables. No thrombotic complications have previously been reported with this drug. Three of the six patients in our study did not receive this drug and none of the children in the study by Gosseye et al was given a similar drug. It is unlikely that this drug alone explains the sequestration of platelet aggregates in the lungs.

Several mechanisms of platelet aggregation may act synergistically in liver transplant recipients and the phenomenon may only become evident clinically when it occurs on such a scale as to cause severe respiratory distress or death. It probably occurs more frequently on a smaller scale with the high fibrinolytic activity of the human lung, ${ }^{22}$ making it of less clinical consequence. Further studies are needed to try and identify those patients who are at particular risk and to avoid any procedures which may precipitate platelet aggregation. The lack of visible thrombus at necropsy may cause the unwary pathologist to dismiss the possibility of thrombosis, but the unusual rubbery consistency and increased weight of the lungs without easily demonstrable pulmonary oedema should alert them to sample the lungs widely and make a detailed search for capillary thrombi. Immunostaining with factor XIIIA and PGIIIa considerably aid the identification of these thrombi.

1 Gosseye S, van Obbergh L, Weynand B, et al. Platelet aggregates in small lung vessels and death during liver transplantation. Lancet 1991;338:532-4.

2 Blaisdell F W, Lim R C, Amberg J R, Choy S H, Hall A D, Thomas A N. Pulmonary microembolism. Arch Surg 1966;93:776-86.

3 Blaisdell F W, Lewis F R Jr. Respiratory distress syndrome of shock and trauma. In: Post-traumatic respiratory failure Philadelphia: Saunders, 1977:49-116.

4 Mallett S V, Cox D, Burroughs A K, Rolles K. The intra- operative use of aprotinin (Trasylol) in liver transplantation. Transplant Int 1991;4:227-30.

5 Jansson I G, Hetland O, Rammer L M, Prydz H E, Lennquist $S$ E. Effects of phospholipase $C$, a tissue thromboplastin inhibitor, on pulmonary microembolism thromboplastin inhibitor, on pulmonary microembolism
after missile injury of the limb. $\mathcal{F}$ Trauma 1988;28 (Suppl 1):S222-S5.

6 Giercksky K E, Biorklid E, Prydz H. The effect of intravenous injection of purified human tissue thromboplastin in rats. Scand $\mathcal{f}$ Haematol 1976;16:300-10.

7 Konstam M A, Brockway B A, Aronovitz M J, et al. Kinetics of pulmonary platelet deposition and clearance during thrombin-induced microembolism in rabbits. Exp Lung Res 1989;15:867-79.

8 McCandless B K, Kaplan J E, Cooper J A, Malik A B. Determinants of platelet kinetics: effects of pulmonary microembolism. $₹$ Appl Physiol 1988;65:1716-22.

9 Gutmann F D, Murthy V S, Wojciechowski M T, Wurm R M, Edzards R A. Transient pulmonary platelet sequestration during endotoxemia in dogs. Circ Shock 1987;21:185-95.

10 Groves A C, Griffiths J, Leung F Y, Naiman S C. Fibrin thrombi in the pulmonary microcirculation of dogs with gram-negative bacteremia. Surg Gynecol Obstet 1972; 134:433-6.

11 Rabinovici R, Esser K M, Lysko P G, et al. Priming by platelet-activating factor of endotoxin-induced lung injury and cardiovascular shock. Circ Res 1991;69: $12-25$.

12 Miyata T, Yokoyama I, Todo S, Tzakis A, Selby R, Starzl $T$ E. Endotoxaemia, pulmonary complications, and T E. Endotoxaemia, pulmonary complications, and thrombocy

13 Bowald S, Gerdin B. Pulmonary microembolism during and after aortic cross-clamping in heparinized and nonheparinized pigs. Acta Chir Scand 1980;146:351-6.

14 Ashford T P. The etiology of venous thrombi after crossclamping: An electron microscopic study. Surgery 1970; 68:846-51.

15 Wedzicha J A, Syndercombe-Court D, Tan K C. Increased platelet aggregate formation in patients with chronic airflow obstruction and hypoxaemia. Thorax chronic airflow

16 Fallon K D, Berman $\mathrm{H} \mathrm{J}$. Effect of $\mathrm{pH}$ on susceptibility to injury-induced platelet thrombosis. Fed Proc 1969;28: injury

17 Rostagno C, Prisco D, Boddi M, Poggesi L. Evidence for local platelet activation in pulmonary vessels in patients with pulmonary hypertension secondary to chronic obstructive pulmonary disease. Eur Resp $\mathcal{f}$ 1991;4: 147-51.

18 Yamamoto $Y$, Hasegawa $H$, Ikeda $K$, Ichiyama $A$ Cervical dislocation of mice induces rapid accumulation of platelet serotonin in the lung. Agents Actions 1988, 25:48-56.

19 Nakamura S, Shimokama T, Yoshikawa Y, Watanabe T. Immune complex-induced disseminated intravascular Immune complex-induced disseminated intravascular coagulation (DIC).

20 Oka K, Tanaka K. Intravascular coagulation in autopsy cases with liver diseases. Thromb Haemostas 1979;42: 564-70.

21 Edwards B S, Weir E K, Edwards W D, Ludwig J, Dykoski R K, Edwards J E. Coexistent pulmonary and portal hypertension: morphologic and clinical features. $\mathcal{f}$ Am Coll Cardiol 1987;10:1233-8.

22 Astrup T, Glas P, Kok P. Thromboplastic and fibrinolytic activity in lungs of some mammals. Lab Invest 1970;22: 381-6. 